\title{
Vitalism as an Epistemological Obstacle to Biochemical Knowledge
}

Almeida, R.V. ${ }^{1}$; Larentis, A.L. ${ }^{2}$; Araújo, L.V. ${ }^{3}$; Cabral, B.C. ${ }^{1}$; Caldas, L.A. ; Da Silva, D.P. ${ }^{1}$; Garcia, C.H.S. ${ }^{1}$; Herbst, M.H. ${ }^{5}$; Kaercher, L.E. ${ }^{6}$; Levy, R.S. ${ }^{1}$; Mannarino, S.C. ${ }^{1}$; Moura, M.V.H. ${ }^{1}$; Nogueira, F.C.S. ${ }^{1}$; Pacheco, G.J. ${ }^{1}$; Paiva, L.M.C. ${ }^{1}$; Pereira, A.G. ${ }^{1}$; Ribeiro, M.G.L. ${ }^{7}$; Ribeiro, T.P. ${ }^{1}$; Sena, M.A.B. ${ }^{1}$; Tavares, L.F.D. ${ }^{1}$; Domont, G.B. ${ }^{1^{*}}$

${ }^{1}$ PPGBq-UFRJ; ${ }^{2}$ Fiocruz; ${ }^{3}$ PPGCA-UFRJ; ${ }^{4}$ IBCCF-UFRJ; ${ }^{5}$ DQ-UFRRJ; ${ }^{6}$ INPI; ${ }^{7}$ IB-UFF, Rio de Janeiro, Brasil, " gilberto@iq.ufrj.br

This work resulted from the study of Gaston Bachelard's epistemology in the Logic and Philosophy of Science discipline, Biochemistry Graduate Program, UFRJ, which lead to discussions of epistemological obstacles on biochemical knowledge construction. The aim was to identify barriers to scientific knowledge development in the praxis of graduate students of biochemistry and correlated areas, emphasizing the vitalist (animist) and teleological (unitary and pragmatic obstacles) conceptions. In order to verify whether students, which never attended classes in epistemology, agree or are able to identify the vitalist conception, a questionnaire containing also selected excerpts of scientific papers in high impact factor journals was delivered to thirty graduating students from different courses at UFRJ and other Brazilian universities. Not only those conceptions were accepted or were not recognized, but it was also possible to observe a vitalist approach in the answers. We could also perceive a pragmatic and teleological vision of the evolution process, expressed in apologies of immanent purposes in organisms adaptations. Considering these facts, it is clear the necessity to emphasize the material, non-teleological character of biochemistry/biology, especially in disciplines offered in under-graduate courses.

Keywords: epistemology, animism, teleology 